Article

\title{
An Index-Based Assessment of Perceived Climate Risk and Vulnerability for the Urban Cluster in the Yangtze River Delta Region of China
}

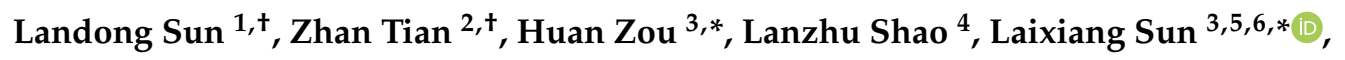 \\ Guangtao Dong ${ }^{1}$, Dongli Fan ${ }^{7}$, Xinxing Huang ${ }^{7}$, Laura Frost ${ }^{4}$ and Lewis-Fox James ${ }^{4}$ \\ 1 Shanghai Climate Center, Shanghai Meteorological Bureau, Shanghai 200030, China; \\ sldlydia@sina.com (L.S.); gtdong@163.com (G.D.) \\ 2 School of Environmental Science and Engineering, Southern University of Science and Technology, \\ Shenzhen 518055, China; tianz@sustc.edu.cn \\ 3 School of Finance and Management, SOAS University of London, London WC1H 0XG, UK \\ 4 Arup 13 Fitzroy Street, London W1T 4BQ, UK; lanzhu.shao@arup.com (L.S.); laura.frost@arup.com (L.F.); \\ lewis-fox.james@arup.com (L.-F.J.) \\ 5 Department of Geographical Sciences, University of Maryland, College Park, MD 20742, USA \\ 6 International Institute for Applied Systems Analysis (IIASA), A-2361 Laxenburg, Austria \\ 7 Shanghai Institute of Technology, Shanghai 200235, China; fandl@sit.edu.cn (D.F.); \\ hxxkrystal@163.com (X.H.) \\ * Correspondence: h.zou@soas.ac.uk (H.Z.); lsun123@umd.edu (L.S.); \\ Tel.: +44-2078984056 (H.Z.); +1-3014058131 (L.S.) \\ + Landong Sun and Zhan Tian contribute equally to this article.
}

Received: 30 January 2019; Accepted: 4 April 2019; Published: 9 April 2019

check for updates

\begin{abstract}
This paper proposes an index-based assessment tool to consolidate diverse opinions of various stakeholders on their assessments of sector-specific risks posed by climate change, and to aggregate these opinions into intuitive and comparable graphs. This tool enables cities to measure and monitor the multiple factors that contribute to their resilience towards climate risk and hazard in the long term. We applied this tool to five key infrastructure sectors in six representative cities in the Yangtze River Delta region. The graphs generated provide for the first time first-hand insights into the aggregative understanding of various stakeholders with regard to the current and future climate risk in their concerned sectors and cities. Our results indicate that a high level of exposure is not automatically associated with a high level of vulnerability across our selected cities. While all cities need to make efforts to reduce their vulnerability towards climate hazards, those characterized by "lower level of exposure but higher level of vulnerability" need to make more urgent and much greater efforts.
\end{abstract}

Keywords: climate risk assessment; index-based; infrastructure; the Yangtze River Delta region; stakeholder perspective

\section{Introduction}

Climate change is considered to increase the frequency and intensity of environmental hazards, largely as a result of simultaneous superposition of weather and climate extremes on a variety of timescales, along with the emergence of new hazards and new vulnerabilities [1]. Climate change has become a critical concern for policy-makers in their strategic planning and decision-making, in addition to the growing concern by scientists and the public [2].

The Intergovernmental Panel on Climate Change (IPCC) [3] defines climate change risk as the combination of the possibility of occurrence of adverse climate events and its consequences, which 
are associated with exposure and vulnerability of the affected groups. It is clear that changed urban climatic conditions drive demands for risk assessment and management so that adaptation and mitigation policies can be made to reduce climate-related uncertainties and risks $[4,5]$.

Literature on climate change risk assessment estimates the extent of climate hazard with climatic projections, as well as the potential impact on human activities, with specific focus on a variety of climate change circumstances, such as flooding [6,7], forest [8], air quality [9], and agriculture [10]. Index-based assessments, as reviewed in Nguyen et al. [11] and Tapia et al. [12], focus on measuring the degree of risk and exposure to hazard, which together determine the level of vulnerability and other issues such as magnitude and duration of the hazardous event. Tate [13] outlines the three sequential steps of vulnerability index construction: the selection of indicators, normalization of indicators to a common scale, and aggregation to a final value. The selection of indicators is driven by theory and data [14,15] based on existing scientific knowledge [16-18] or statistical relationship with observed vulnerability outcomes $[19,20]$. While such scientific fact finding research does improve our understanding of vulnerability across impact chains, existing studies are subject to external validity; given that different decision contexts and scales are context-specific. This can be quite problematic if the aim is to explicitly map vulnerability across broad spatial scales [21,22]. To develop a vulnerability index, not only must you simplify a number of complex and interacting parameters from existing databases, but also integrate them with subjective individual or collective expert opinions to provide the vulnerable system and the forward-looking aspect of vulnerability [11,15], e.g., the Delphi method. In so doing, expert opinions can be complemented through the science-policy interface to acknowledge uncertainty, high stakes, and dissent in assessing climate change risk $[1,23]$ to deliver effective management tools for policy-makers.

Based on the above recognition, this paper focuses on developing an index-based climate change risk assessment tool to serve the following purposes. (1) To collect consistent, organized input from urban infrastructure managers and other adaptation practitioners; (2) to facilitate collaboration and, where possible, the sharing of information and knowledge across governmental departments, which has been very difficult in many cities in the world; (3) to consolidate diverse opinions of various stakeholders on their assessments of sector-specific risks posed by climate change and to aggregate these opinions into intuitive and comparable graphs. This tool enables a municipal government to effectively and consistently collect, consolidate, and aggregate knowledge and perceptions of its officials, who are in charge of infrastructure planning and operation, and other stakeholders in identifying climate hazards and the associated risks to specific critical infrastructure systems, going beyond the impact of climate change through extreme events. In this way, the paper fills a critical gap by crafting a risk assessment tool for cities that synthesizes existing local information, expert opinions, and scientific tools.

According to China Meteorological Disasters Dictionary [24-26], the Yangtze River Delta (YRD)—one of the largest urban agglomerations in the world and urban cluster in the region-is afflicted with a number of climate disasters like typhoon [27], floods induced by heavy rain [28], and prolonged high temperatures [29]. Studies in this region on climate risk assessment mainly rely on meteorological data and macroeconomic indices to evaluate the driving factors of climate vulnerability in the selected cities $[27,30]$.

To provide complementary subjective perspectives, we selected six cities in the region for this study. There are two main reasons. First, methodologically, we provide complementary subjective expert opinions in addition to scientific projections by adopting an index-based approach. Focusing on the selected region and the key sectors, we are able to clearly define the system of analysis [15]. Second, the observed climate change in the past decades has exerted significant impacts on the regional urban agglomeration and the future climate change may trigger more extreme weather events, which will have substantial impact on the flood control, energy saving, and environment protection across cities in the region [30]. Therefore, it is of great importance for municipal governments in the urban cluster of the region to enhance their capacity in synthesizing the existing local information, expert opinions, 
and scientific tools, so that they can implement well-informed and proactive infrastructure planning to mitigate the forthcoming risks posed by climate change. Moreover, the development of our index-based climate change risk assessment framework has been a coproduction process with the engagement of different stakeholders in the region. This coproduction process together with the index-based risk assessment framework has general applicability for cities in other regions and countries.

\section{The Study Area and Focal Hazards}

The Yangtze River Delta urban agglomeration (hereinafter referred to as the YRD urban agglomeration) is composed of 26 cities with Shanghai as the core (Figure 1). The Delta closely links Shanghai, Jiangsu, Zhejiang, and Anhui provinces together in terms of production supply chains. It is the most developed region in China with the highest degree of urban agglomeration. This most urbanized area has played a pivotal strategic role in the process of economic development and modernization in China. The YRD urban agglomeration is one of the largest urban agglomerations in the world and is the most important population and economic center of China, with high energy consumption and a significant urban heat island effect [31]. The meteorological and climate disasters that have a significant impact on the operation of the YRD urban agglomeration include: heat waves, typhoons, local heavy rainfall, thunderstorms, heavy fog, and strong winds [32]. For instance, heat waves are likely to cause tensions in urban power supply and water supply, frequent traffic accidents, reduced production of crops and vegetables, and heatstroke and diarrhea, which have a great impact on human health and safe operation of the urban systems. A recent IPCC study ranked Shanghai as one of the top 30 cities in the world in terms of population exposure and economic assets exposure to floods [33]. It is recommended that information sharing and coordinating capacity of local government agencies are critical in mitigating the potential devastating consequences of meteorological and climate hazards in the YRD urban agglomeration.

It is worth noting that cities in the region are quite diverse in terms of land area, population, and the level of economic development. It is an important research agenda to understand the variations of key climate change impacts across different cities in the region. The six cities we selected for this research are Shanghai, Zhenjiang, Nanjing (along the Yangtze River upstream), Hangzhou, Ningbo, and Hefei (Figure 1). Shanghai is the core of the whole region. Nanjing, Hangzhou, and Hefei are capital cities of Jiangsu, Zhejiang, and Anhui provinces, respectively. These four cities were selected for their political economy importance in the region. Zhenjiang was selected as a representative of medium-sized cities and Ningbo was selected because it is emerging as the second important city in Zhejiang Province.

In preparing for the research, we scoped the current disaster situation in the region using data from the Shanghai Climate Center. We checked the conventional meteorological observation data of the cities in the Yangtze Delta Region in the past fifty years to identify disaster events such as heavy rain, typhoon, high temperature, flooding, thunderstorm, fog, hail, low temperature, and drought. According to the frequency, occurrence intensity, impact range, and economic losses caused by these meteorological disasters, four, as presented in Table 1, are identified as the most eminent. Typhoons have a wide range of impacts on every aspects of urban life and can cause very serious losses. Heavy rainstorms often lead to urban floods and cause disruptions to urban transportation and socioeconomic activities. High temperature heat waves and cold spells are likely to cause heatstroke, significantly increase peak loading of urban power supply, and lead to traffic accidents and water shortages. Frequent traffic accidents, heatstroke, diarrhea, and other diseases have a greater impact on the safe operation of the city. 




Figure 1. Yangtze River Delta urban agglomeration and the six case-study cities.

Table 1. The key features of the six representative cities in the Yangtze River Delta and major adverse meteorological events in these cities.

\begin{tabular}{|c|c|c|c|}
\hline City & $\begin{array}{l}\text { Resident Population } \\
\quad(10,000 \text { People) }\end{array}$ & Scale & Major Meteorological Disaster \\
\hline Shanghai & 2418.33 & Megacity & Rainstorm, typhoon, heat waves. \\
\hline Nanjing & 833.5 & \multirow{4}{*}{ Big City } & Rainstorm, typhoon. heat waves, cold spells \\
\hline Hangzhou & 946.8 & & Rainstorm, typhoon, heat waves, cold spells \\
\hline Hefei & 796.5 & & Rainstorm, typhoon, heat waves, cold spells \\
\hline Ningbo & 800.5 & & Rainstorm, typhoon, heat waves, cold spells \\
\hline Zhenjiang & 318.63 & Medium-sized City & Rainstorm, typhoon, heat waves, cold spells \\
\hline
\end{tabular}

Typhoon landfall is regarded as the number one meteorological disaster affecting the infrastructure of the Yangtze River Delta urban agglomeration [24-26]. In the next 30 years, typhoon landfalls on the Yangtze River Delta will be highly likely to have an increasing trend [27]. Rainstorms and urban inundation caused by heavy rainfall are second to typhoons. In the future, the days of heavy precipitation and the intensity of heavy precipitation will show an increasing trend with high probability. Heat wave events are also going to have higher frequency and stronger intensity in the future, along with the global warming [31,32]. At present, urban infrastructure in the six 
cities is mainly exposed to typhoons and heavy rainfalls. In the future, urban infrastructure will also become more vulnerable to heat wave events. These assessment outcomes on climate change were communicated with the participants in the focus group meetings at the beginning of each meeting.

\section{Method and Data Collection}

\subsection{Future Climate Change Projections}

Based on the scope of studies on historical disaster events, we adopted the global circulation model of the UK Met Office, HadGEM2-ES [34-36], to drive the high-resolution regional climate model of the UK Met Office, PRECIS-2, and carried out a 30-year (1971-2000) simulation capability assessment for the Yangtze River Delta region. On this basis, we used HadGEM2-ES under the RCP45 and RCP85 scenarios to drive PRECIS-2 to carry out climate projections for 2006-2060. We then employed the PRECIS-2 projections for the next three decades (2021-2050) to observe basic and extreme climate changes in the YRD urban agglomeration. The baseline climatology in our research is the average climate over 1971-2000. The major outputs of our future climate change projections are presented in the Supplementary Materials of this paper. Our tool is designed to encourage collaborating and sharing information and knowledge across governmental departments. Therefore, we employed focus group discussions as the most important means to collect input from urban infrastructure managers and other adaptation practitioners. Each our focus group meetings started with our presentation on these climate projections.

\subsection{Focus Group Meetings to Collect Key Input to the CIAT Analysis Tool}

During March 2017 to October 2018, the research team hosted expert focus group meetings and consultations in six cities including Shanghai, Hangzhou, Nanjing, Hefei, Ningbo, and Zhenjiang. Owing to the attractiveness of our research project to city government agencies in the region and the strong networking ability of our research team, we obtained unique access to a large pool of experts and decision-makers in critical urban sectors in these six cities. In these meetings we met with more than 70 experts in five key infrastructure sectors: transportation (covers road systems, subway/light rail, railway systems, port terminals, and civil aviation airports), water (includes tap water systems, water systems and treatment facilities, sewage systems and treatment facilities, flood control facilities (river dikes and seawalls), main lift pumping stations (tap water, water, sewage, and rainwater), and water systems (rivers and lakes)), energy (substations, transmission systems, distribution systems, and power plants), telecommunications (core equipment rooms, module offices and towers, and base stations), and civil administration buildings (police stations, hospitals, emergency shelters, schools, kindergartens, and fire stations). We received 67 valid questionnaires during and after these meetings. Of these 67 valid questionnaires, 14 are from Shanghai, 11 from Hangzhou, nine from Zhenjiang, 10 from Nanjing, eight from Ningbo, and 15 from Hefei. Consequently, we systematically collected the relevant information and data on climate risks and vulnerability perceived by infrastructure managers and other stakeholders in the adaptation field, which are indispensable for performing an integrated risk assessment. They answered a number of questions across three discrete categories that are considered crucial for ensuring the proper functioning of the assets. Then we developed an assessment tool to assess the climate hazards and their impacts on infrastructure for the region, known as the (Yangtze River Delta) Climate and Infrastructure Assessment Tool (CIAT), based on the answers and the notes taken in the focus group discussions. To our knowledge, the data collection is quite comprehensive in approaching diverse opinions of various stakeholders who are able to assess sector-specific risks posed by climate change based on their knowledge and experiences. The results are drawn from these opinions into intuitive and comparable graphs. 


\subsection{The Climate and Infrastructure Assessment Tool (CIAT) and Questionnaire}

The workflow scheme of the CIAT is presented in Figure 2. Module 1 of the CIAT is a Climate Risk Assessment. Modules 2a, 2b, and 3 are an Infrastructure Assessment, including the assessments of exposure, vulnerability, and interdependency.

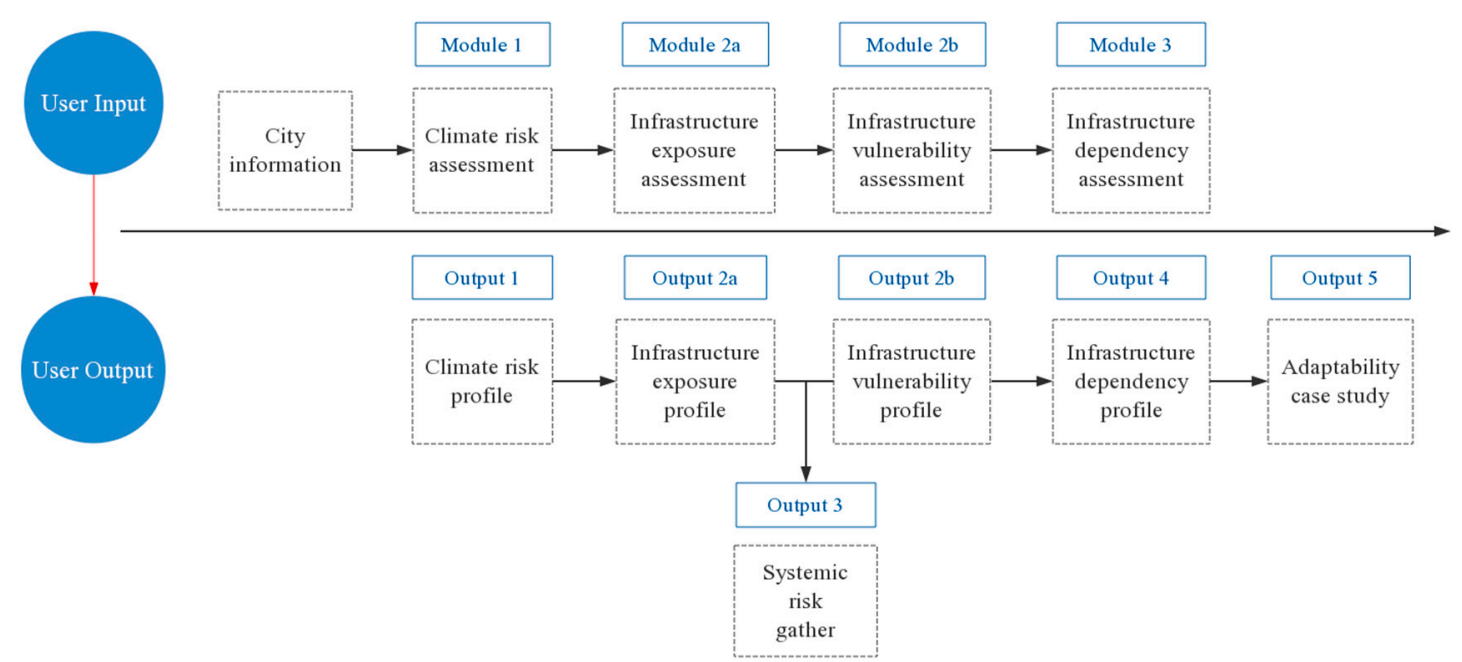

Figure 2. The workflow scheme of the Climate and Infrastructure Assessment Tool (CIAT).

Module 1 commences with a selection process that filters the set of climate hazards between the 2020s and the 2050th by focusing on those that are highly likely to occur in the region. The filtering process highlights a shorter list of climate hazards for more detailed examination. The module then employs the conventional Risk Matrix (i.e., Risk $=$ Severity $\times$ Likelihood) to produce a comparable, relative risk value for each climate hazard. The 'Severity' score of each climate hazard is a fixed value between 1 and 5 . Where possible, the climate hazards have been standardized in line with internationally recognized conventions. For example, a 'moderate' tornado represents an Enhanced Fujita scale F0 or F1 hazard and a 'severe' tornado is for a F2 or greater event. The fixed 'Severity' scores for each climate hazard were established in a workshop by discussions between local stakeholders and our research team in climate studies. The climate hazard 'Likelihood' score also comprises values between 1 and 5, however it is entered by the users, as a result of the corresponding focus group discussion, for the 'Current' period in '30 years' and in '50 years', respectively. The user is encouraged to provide evidence or a justification narrative to support the assigned 'Likelihood' score. Having been assigned a Risk score out of 25 (i.e., Severity (out of 5) $\times$ Likelihood (out of 5)) the results are then plotted on a Likelihood vs. Severity graph for each of the three time periods stated above. The users are then required to select a maximum of four climate hazards for inclusion in the Infrastructure Assessment.

The Infrastructure Assessment aims to assess the major risk features of major city infrastructures when confronting climate hazards such as heat wave, rainstorm, and typhoon. It comprises three stages: Exposure evaluation (Module 2a), Vulnerability evaluation (Module 2b), and Interdependency evaluation (Module 3). The full list of major infrastructure assets (e.g., major roads and railways) is grouped into infrastructure systems (e.g., transport systems) for assessment of interdependency.

Each infrastructure asset is assessed in terms of its exposure to each of the four climate hazards selected in the climate hazard assessment process. The levels of exposure, each with a preassigned score, are selected by the users from a discrete list of low, medium, and, high. The levels of exposure are standardized by a narrative for consistency. The Infrastructure 'Exposure' assessment considers each asset in the 'Current' period as well as the 'Future'. Unlike for the Climate Assessment, it is not anticipated that information of sufficient quality or granularity is available for assessing future exposure in more precise terms. This explains why the 30- and 50-year periods are replaced with 
the more generic 'Future'. The infrastructure asset's exposure to each of the four climate hazards can still be assessed. Table 2 demonstrates the assessment process using the transportation sector in Shanghai as an example. We invited experts who are senior engineers, departmental directors, and policy researchers in each of the five infrastructure sectors and also in urban planning departments of the municipal governments. These experts have comprehensive industry experience and have a high awareness of climate change risks. They attended our focus group meeting and, after in-depth discussions, provided their evaluation on to what extent the performance of the infrastructure asset in assessment can be compromised by current vs future climate hazards. Then the climate hazard for each infrastructure asset with the greatest 'Exposure' score is carried through into the Infrastructure Vulnerability Assessment and is labeled the 'Critical climate hazard'.

The Infrastructure Vulnerability Assessment then assesses each infrastructure asset against its respective 'critical climate hazard'. The senior experts answered a number of questions across three discrete categories that are considered crucial for ensuring the proper functioning of the assets. The categories are Planning and Design, Operation and Maintenance, and Future Vulnerability. The Planning and Design category indicates whether the facility carries out environmental and climate risk assessment in the planning and design process, whether it considers climate disasters during the design stage and whether there are protective facilities (such as flood control walls), which will mitigate the impact of related disasters in future. The Operation and Maintenance category relates to existing monitoring mechanism to maintain performance and operation; emergency response and recovery mechanism to ensure rapid reconstruction when the system no longer functions; regular maintenance scheme to ensure effective operation; and upgrading programs and plans to accommodate urban climate trends and population growth. Future Vulnerability includes a comprehensive consideration of future climate hazards, and the climate expert consultation process which takes into account climate change and exposure.

Similar to the data collection through focus group meetings, Vulnerability Assessments are also based on expert symposia which offered comprehensive judgments on the various infrastructure sectors in the city. Vulnerability from low to high is represented by the numbers 1 to 3 , and the definition of the vulnerability level is provided within the CIAT tool. Table 3 presents the example of a questionnaire answer sheet on the vulnerability of Shanghai's infrastructure in the transportation sector. As shown in Table 3, in the Planning and Design panel, respondents provided their answers to (a) whether for the infrastructure, an assessment on environmental and climate risks had been done during the planning and design process; (b) which hazard risk were considered in the design; and (c) the presence of defense facility against the major hazards. Based on the experience and understanding of the respondents, they gave out the corresponding answers through the drop-down list. We then performed the CIAT tool to check the overall vulnerability of the infrastructure, showing the most relevant climate hazard associated with the city.

The third and final stage of the infrastructure assessment is the assessment of system vulnerability. As described earlier, the individual assets have been grouped into 'systems' (i.e., transport, water, and energy) for describing the interdependency of each infrastructure system against the other. The options of low, medium or high interdependency compile an overall score of interdependency for each infrastructure system. 
Table 2. Questionnaire about climate change exposure of major traffic infrastructures: The case of Shanghai.

\begin{tabular}{|c|c|c|c|c|c|c|c|c|c|c|c|c|c|c|c|c|c|c|c|c|c|c|c|c|}
\hline & \multicolumn{6}{|c|}{ Flood } & \multicolumn{6}{|c|}{ Heat Wave } & \multicolumn{6}{|c|}{ Rainstorm } & \multicolumn{6}{|c|}{ Typhoon } \\
\hline & \multicolumn{3}{|c|}{ Current } & \multicolumn{3}{|c|}{ Future } & \multicolumn{3}{|c|}{ Current } & \multicolumn{3}{|c|}{ Future } & \multicolumn{3}{|c|}{ Current } & \multicolumn{3}{|c|}{ Future } & \multicolumn{3}{|c|}{ Current } & \multicolumn{3}{|c|}{ Future } \\
\hline & High & Mid & Low & High & Mid & Low & High & Mid & Low & High & Mid & Low & High & Mid & Low & High & Mid & Low & High & Mid & Low & High & Mid & Low \\
\hline Main road & $\sqrt{ }$ & & & $\sqrt{ }$ & & & & $\sqrt{ }$ & & $\sqrt{ }$ & & & $\sqrt{ }$ & & & $\sqrt{ }$ & & & $\sqrt{ }$ & & & $\sqrt{ }$ & & \\
\hline Main Tunnel & & $\sqrt{ }$ & & $\sqrt{ }$ & & & & $\sqrt{ }$ & & $\sqrt{ }$ & & & $\sqrt{ }$ & & & $\sqrt{ }$ & & & & $\sqrt{ }$ & & & $\sqrt{ }$ & \\
\hline Subway & $\sqrt{ }$ & & & $\sqrt{ }$ & & & & $\sqrt{ }$ & & & $\sqrt{ }$ & & $\sqrt{ }$ & & & $\sqrt{ }$ & & & & $\sqrt{ }$ & & & $\sqrt{ }$ & \\
\hline Port & & & $\sqrt{ }$ & & $\sqrt{ }$ & & & $\sqrt{ }$ & & & $\sqrt{ }$ & & & $\sqrt{ }$ & & $\sqrt{ }$ & & & $\sqrt{ }$ & & & $\sqrt{ }$ & & \\
\hline Airport & & $\sqrt{ }$ & & & $\sqrt{ }$ & & & $\sqrt{ }$ & & & $\sqrt{ }$ & & $\sqrt{ }$ & & & $\sqrt{ }$ & & & $\sqrt{ }$ & & & $\sqrt{ }$ & & \\
\hline
\end{tabular}

Table 3. Questionnaire about the vulnerability of Shanghai's Infrastructure in the Transportation Sector.

\begin{tabular}{|c|c|c|c|c|c|c|c|c|c|c|}
\hline \multicolumn{2}{|c|}{ Description } & \multicolumn{3}{|c|}{ Planning and Design } & \multicolumn{4}{|c|}{ Operation and Maintenance } & \multicolumn{2}{|c|}{ Future Vulnerability } \\
\hline Infrastructure & $\begin{array}{l}\text { Main Climate } \\
\text { Disaster }\end{array}$ & $\begin{array}{l}\text { Environmental and } \\
\text { Climate Risks } \\
\text { Assessment }\end{array}$ & Risk Design & Defense Facility & $\begin{array}{l}\text { Monitoring } \\
\text { Mechanism }\end{array}$ & $\begin{array}{l}\text { Emergency } \\
\text { Mechanism }\end{array}$ & $\begin{array}{c}\text { Regular } \\
\text { Maintenance }\end{array}$ & Regularly Updated & $\begin{array}{c}\text { Climate } \\
\text { Consultation }\end{array}$ & $\begin{array}{l}\text { Medium/Long } \\
\text { Term Climate } \\
\text { Change }\end{array}$ \\
\hline Main road & $\begin{array}{l}\text { Flood/heat wave/ } \\
\text { rainstorm/typhoon }\end{array}$ & $\begin{array}{l}\text { Experts were } \\
\text { consulted about } \\
\text { current risks }\end{array}$ & $\begin{array}{l}\text { Partly and/or } \\
\text { some hazards }\end{array}$ & $\begin{array}{l}\text { Protective } \\
\text { infrastructure for } \\
\text { highlighted } \\
\text { hazards }\end{array}$ & $\begin{array}{l}\text { Infrequent } \\
\text { monitoring }\end{array}$ & $\begin{array}{c}\text { Effective } \\
\text { procedures in } \\
\text { place, regularly } \\
\text { reviewed }\end{array}$ & $\begin{array}{c}\text { Irregular } \\
\text { maintenance } \\
\text { undertaken }\end{array}$ & $\begin{array}{l}\text { Upgraded to } \\
\text { accommodate new } \\
\text { technologies only }\end{array}$ & $\begin{array}{l}\text { Consulted but } \\
\text { not fully }\end{array}$ & $\begin{array}{l}\text { Designed for } \\
\text { predicted } 30 \text { year } \\
\text { changes but not } \\
50 \text { year changes }\end{array}$ \\
\hline Main Tunnel & $\begin{array}{l}\text { Flood/heat wave/ } \\
\text { rainstorm/typhoon }\end{array}$ & Don't know & $\begin{array}{l}\text { All hazards } \\
\text { were considered }\end{array}$ & $\begin{array}{c}\text { Protective } \\
\text { infrastructure in } \\
\text { place for all } \\
\text { relevant hazards }\end{array}$ & $\begin{array}{l}\text { Continuous } \\
\text { monitoring } \\
\text { using smart } \\
\text { technology }\end{array}$ & $\begin{array}{c}\text { Procedures exist } \\
\text { but rarely } \\
\text { checked/tested }\end{array}$ & $\begin{array}{c}\text { Appropriate, } \\
\text { regular } \\
\text { maintenance }\end{array}$ & $\begin{array}{l}\text { Upgraded for new } \\
\text { technologies and } \\
\text { changes in } \\
\text { environmental \& } \\
\text { social conditions }\end{array}$ & $\begin{array}{l}\text { Consulted as part } \\
\text { of a collaborative } \\
\text { planning process. }\end{array}$ & Don't know \\
\hline Subway & $\begin{array}{l}\text { Flood/heat wave/ } \\
\text { rainstorm/typhoon }\end{array}$ & $\begin{array}{l}\text { Full risk assessment } \\
\text { done for current } \\
\text { and future risks }\end{array}$ & $\begin{array}{l}\text { All hazards } \\
\text { were considered }\end{array}$ & $\begin{array}{l}\text { Protective } \\
\text { infrastructure for } \\
\text { highlighted } \\
\text { hazards }\end{array}$ & $\begin{array}{l}\text { Infrequent } \\
\text { monitoring }\end{array}$ & $\begin{array}{c}\text { Procedures exist } \\
\text { but rarely } \\
\text { checked/tested }\end{array}$ & $\begin{array}{c}\text { Irregular } \\
\text { maintenance } \\
\text { undertaken }\end{array}$ & $\begin{array}{l}\text { Upgraded to } \\
\text { accommodate new } \\
\text { technologies only }\end{array}$ & $\begin{array}{l}\text { Consulted but } \\
\text { not fully }\end{array}$ & $\begin{array}{l}\text { Designed for } \\
\text { predicted } 50 \text { year + } \\
\text { changes }\end{array}$ \\
\hline Port & $\begin{array}{l}\text { Flood/heat wave/ } \\
\text { rainstorm/typhoon }\end{array}$ & Don't know & $\begin{array}{l}\text { Partly and/or } \\
\text { some hazards }\end{array}$ & $\begin{array}{c}\text { Protective } \\
\text { infrastructure in } \\
\text { place for all } \\
\text { relevant hazards }\end{array}$ & $\begin{array}{l}\text { Continuous } \\
\text { monitoring } \\
\text { using smart } \\
\text { technology }\end{array}$ & $\begin{array}{c}\text { Effective } \\
\text { procedures in } \\
\text { place, regularly } \\
\text { reviewed }\end{array}$ & $\begin{array}{c}\text { Appropriate, } \\
\text { regular } \\
\text { maintenance }\end{array}$ & $\begin{array}{l}\text { Upgraded for new } \\
\text { technologies and } \\
\text { changes in } \\
\text { environmental } \\
\text { \&social conditions }\end{array}$ & $\begin{array}{l}\text { Consulted but } \\
\text { not fully }\end{array}$ & $\begin{array}{l}\text { Designed for } \\
\text { predicted } 50 \text { year }+ \\
\text { changes }\end{array}$ \\
\hline Airport & $\begin{array}{l}\text { Flood/heat wave/ } \\
\text { rainstorm/typhoon }\end{array}$ & $\begin{array}{l}\text { Experts were } \\
\text { consulted about } \\
\text { current risks }\end{array}$ & $\begin{array}{c}\text { All hazards } \\
\text { were considered }\end{array}$ & $\begin{array}{l}\text { Protective } \\
\text { infrastructure for } \\
\text { highlighted } \\
\text { hazards }\end{array}$ & $\begin{array}{l}\text { Infrequent } \\
\text { monitoring }\end{array}$ & $\begin{array}{c}\text { Effective } \\
\text { procedures in } \\
\text { place, regularly } \\
\text { reviewed }\end{array}$ & $\begin{array}{l}\text { Irregular } \\
\text { maintenance } \\
\text { undertaken }\end{array}$ & $\begin{array}{l}\text { Upgraded to } \\
\text { accommodate new } \\
\text { technologies only }\end{array}$ & $\begin{array}{l}\text { Consulted but } \\
\text { not fully }\end{array}$ & $\begin{array}{l}\text { Designed for } \\
\text { predicted } 50 \text { year }+ \\
\text { changes }\end{array}$ \\
\hline
\end{tabular}




\section{Results and Discussions}

\subsection{Infrastructure Exposure Assessment}

Through the analysis of the questionnaires obtained from the focus group and expert consultations in the CIAT tool, we were able to identify the top four adverse climate events in the selected cities. Take Shanghai as a snapshot, the major climate hazards include typhoons, heavy rainfall, urban floods caused by heavy rainfall, and high temperature heat waves. The assessment results on current and future exposure levels for the five major infrastructure sectors in the six selected cities are summarized in the pentagonal graphs shown in Figure 3. We first compare the exposure level of each sector across the six cities and then compare the exposure levels across the five sectors in each city.

$\mathrm{T}$ represents the transportation sector. Figure 3 shows that currently, Nanjing has the highest exposure level in the transportation sector, followed by Shanghai, Zhenjiang, Hangzhou, Ningbo, and Hefei. With the projected climate change in the 2050s, although the city order of exposures in the transportation sector will remain unchanged, the extent of change will have a different order. Hangzhou's exposure is going to increase most significantly in comparison to the status quo, followed by changes in Nanjing, Hangzhou, Shanghai, Ningbo, Hefei, and Zhenjiang. Why does transportation in Nanjing have the highest exposure? Expert opinions indicate that different from other five cities, Nanjing's territory extends $150 \mathrm{~km}$ along both banks of the Yangtze River, and this specific geographical feature makes Nanjing's transportation sector highly exposed to flooding and other meteorological hazards.

\section{Cumulative System Exposure}
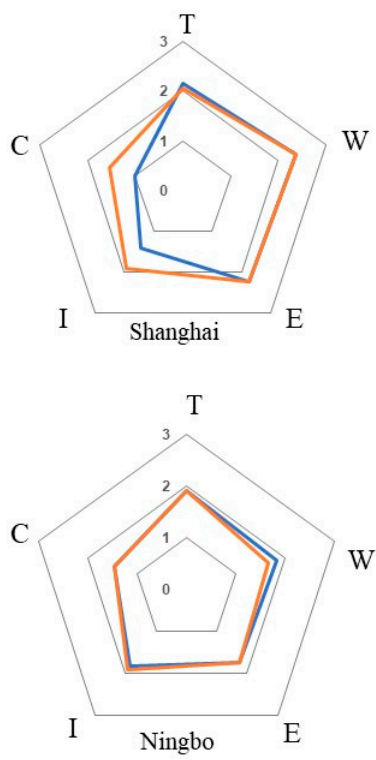



Figure 3. Cumulative exposure to meteorological/climate hazard risks in the five major infrastructure sectors (transportation, water, energy, information and communication, and civil administration buildings) in the six selected cities of the Yangtze River Delta Region.

W represents the water sector. Among the six selected cities in the Yangtze River Delta, currently Shanghai has the highest exposure in the water sector, followed by Hangzhou, Hefei, Nanjing, Ningbo, and Zhenjiang. Under the projected climate change in the 2050s, the city order of exposures will remain; however, the exposure levels of Zhenjiang and Ningbo will decrease, and those of the other four cities will increase to varying degrees, in descending order from Hangzhou, Hefei, Shanghai, to Nanjing. 
In the energy sector (E), currently, Shanghai has the highest exposure level among the six representative cities, followed by Hangzhou, Ningbo, Nanjing, Zhenjiang, and Hefei. This order is going to remain under the projected climate change in the 2050s. However, the extent of changes will have a different city order. The exposure levels of Hangzhou and Nanjing will decrease, whereas the exposure levels of the other four cities will increase to varying degrees, with Hefei playing the leading role.

In the information and communication sector (I), Nanjing and Hangzhou currently experience the highest levels of exposure, followed by Hefei, Zhenjiang, Ningbo, and Shanghai. In the 2050s, the exposure levels of Shanghai will increase significantly, followed by Hangzhou, Ningbo, and Zhenjiang, whereas the exposure level of Nanjing and Hefei will decrease.

In terms of the current exposure of the civil administration building (C), Hangzhou has the highest level, Shanghai and Nanjing have the lowest level, and Ningbo, Zhenjiang, and Hefei are in the middle. With the projected climate change in the 2050s, the exposure level of Hangzhou will increase further and that of Shanghai and Nanjing will increase significantly to exceed the level of Ningbo and Zhenjiang. By contrast, the exposure level will increase by a small margin in Hefei and Zhenjiang and will keep unchanged in Ningbo.

To compare the exposure levels across the five sectors in each city, first, we present the results of Shanghai. Under the current situation, the order of climate risk exposure across Shanghai's urban infrastructure sectors is water sector $>$ energy sector $>$ transportation sector $>$ telecommunications sector $>$ civil administrative buildings. The order of climate risk exposure across these five sectors will remain unchanged and the exposure level of the transportation sector will decrease slightly. In the future the exposure level of the information and communications sector, and civil administrative buildings sector will increase by a significant margin. As a result, the overall risk exposure of Shanghai's urban infrastructure will increase significantly by the 2050s.

In the case of Hangzhou, Figure 3 shows that under the current situation, the civil administrative buildings sector faces the highest level of exposure, followed by the water, telecommunications, transportation, and energy sectors. This order is in sharp contrast to the case of Shanghai. In the 2050s, the order of climate risk exposure across the five sectors of urban infrastructure is not going to change. However, the exposure level of the communications sector and civil administrative buildings sector is expected to increase by a significant margin.

For Nanjing, currently the transportation sector tops the level of climate risk exposure, followed by information and communications, water, energy, and civil administrative buildings. In comparison with the other five cities, the variation of exposure across the five sectors is largest in Nanjing. In the 2050s, there will be no shift in the ranking of climate risk exposures across the five sectors. The transportation sector will still have the highest degree of exposure to climate change risks, and the exposure levels in in the water, energy, and telecommunications sectors will be reduced by a moderate margin. By contrast, the exposure of the civil administrative buildings sector is expected to increase significantly.

In comparison with the cases of Shanghai, Hangzhou, and Nanjing, all five sectors in Ningbo currently face moderate level of exposure to climate hazard risk and this pattern of exposure will remain by the 2050s. A similar observation also holds for Zhenjiang For Hefei, although all sectors face moderate exposure to climate hazard risks currently and this extent of exposure will continue in the 2050s, the exposure level in the energy sector will increase significantly by the 2050s.

\subsection{Infrastructure Vulnerability Assessment}

Figure 4 presents the assessment of the climate hazard vulnerability across the five major infrastructure sectors in the six selected cities. 
Overall System Level Vulnerability


Figure 4. The vulnerability of urban infrastructure (transportation, water, energy, information and communication, and civil administration buildings) to meteorological/climate hazard risks in the six cities.

In the Transportation sector, Hefei faces the highest vulnerability, followed by Zhenjiang, Ningbo, Nanjing, Shanghai, and Hangzhou. By the 2050s, only Shanghai is expected to have a higher vulnerability towards the climate hazards, and vulnerability in the other five cities is very likely to decrease by a varying small margin.

In the Water sector, Nanjing, Hefei, and Ningbo are currently the top one to three most vulnerable cities, followed by Ningbo, Hangzhou, and Shanghai. The vulnerability of future water sector in the six cities will have moderately changes by varying degrees. Zhenjiang will have a relatively more significant increase in water vulnerability, while water vulnerability in Shanghai and Ningbo will hardly change, and the other three cities are expecting slight reduction in water vulnerability.

In the Energy sector, Hefei currently again faces the highest vulnerability, followed by Ningbo, Nanjing, Zhenjiang, Hangzhou, and Shanghai. By the 2050s, except for the slight decrease in the vulnerability of Hefei, the vulnerabilities of the energy sector in the other five cities are expected to increase by relatively a significant margin, with Ningbo ranking the number one.

In the Information and Communication sector, Zhenjiang currently faces the highest vulnerability, followed by Hangzhou, Nanjing, Hefei, Shanghai, and Ningbo. In the 2050s, the vulnerability seems to decrease in Zhenjiang slightly while increasing in the other five cities by varying degrees, with Hangzhou and Ningbo leading the increase.

In the Civil Administrative Buildings sector, Ningbo is currently the most vulnerable and Zhenjiang is the least vulnerable city among the six cities. In the next 30 years, except for the Civil Administrative Buildings sector, vulnerability in Nanjing will decrease by a small margin; all of the other five cities are likely to experience slight increase in vulnerability towards climate hazards.

We can also discover the variation in vulnerability across the five sectors in each city. For example, in the case of Shanghai, the Civil Administrative Buildings is the most vulnerable sector under the current climate conditions, followed by the Transportation, Telecommunications, Water, and Energy sectors. In the future, the Civil administrative buildings sector will continue to have a high level of vulnerability to climate change risks, and the vulnerability in the transportation and energy sectors will increase by a relatively significant margin. To save space, we will not present a similar discussion for the remaining five cities. 


\subsection{Analysis of Exposure versus Vulnerability in the Five Infrastructure Sectors}

Figure 5 presents a comprehensive visualization of risk distribution maps in terms of exposure versus vulnerability in the five infrastructure sectors for each of the six cities. The climate risks across these six cities are quite diverse. The map of Shanghai shows a distribution of high exposure and low vulnerability. It means that, on the one hand, Shanghai's infrastructure is highly exposed to climate hazard risks owing to its geographical location (Figure 1), for instance, being surrounded on three sides by water, including the East China Sea, the Yangtze River Estuary, and Hangzhou Bay. On the other hand, Shanghai is less vulnerable due to that the city has economic strength to adopt the highest standards in infrastructure designing and construction and also to run regular monitoring and maintenance, in comparison with other cities in China. This indicates high capacity of Shanghai in current climate risk management and in future adaptation. Compared with other cities, Shanghai has shown a strong link between the socioeconomic development and the climate risk management in its urban infrastructure design, construction, and maintenance. The infrastructure, as a critical foundation to support the urban development, shows how effectively it can safeguard socioeconomic development once climate change and climate hazard risks are taken into account in the comprehensive process of urban design, operations, maintenance, and upgrades. This distribution of high exposure and low vulnerability is also witnessed in Hangzhou and Nanjing, other two relatively large cities with economic development levels far higher than other smaller cities in the region. In contrast, Zhenjiang, which is located in the inland area of the Yangtze River Delta, has a relatively weaker position in terms of both geographical location and economic development. In the past, the impact of climate change was not put as an important factor in its urban development planning and operations. This leads to a distribution of medium exposure and higher vulnerability as show in Figure 5, indicating potentially high climate hazard risk in its infrastructure sector in the coming decades. The case of Hefei is similar to Zhenjiang.
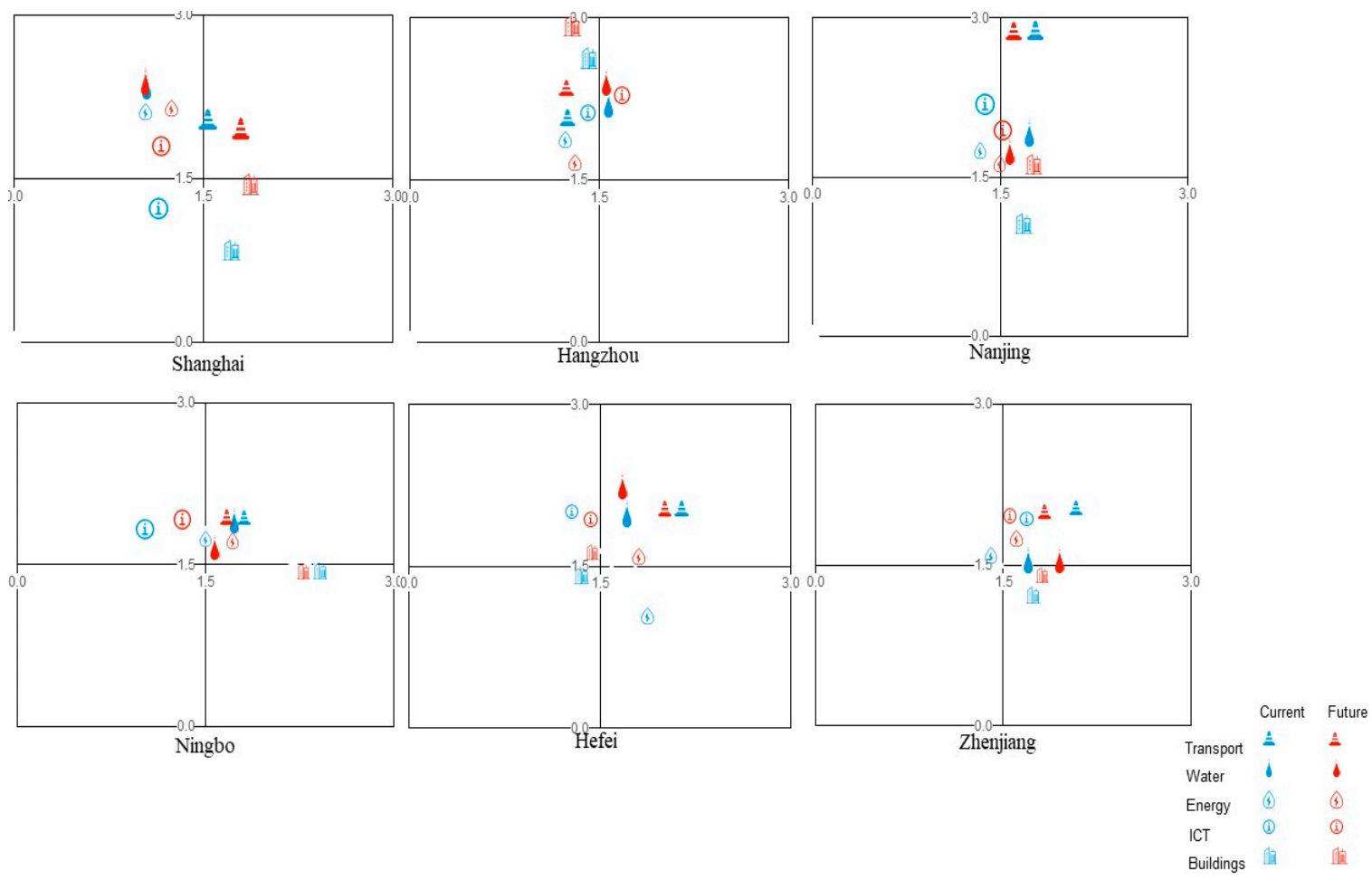

Figure 5. Exposure (vertical axis) versus vulnerability (horizontal axis) in the five infrastructure sectors (transport, water, energy, communications, and urban buildings) by city. 


\section{Conclusions}

This paper aims to provide an index-based climate risk assessment framework, which enables cities to measure and monitor the multiple factors that contribute to their resilience towards climate risk and hazard in the long term. The index-based framework provides a holistic articulation of city resilience, structured around four dimensions, 12 goals, and 52 indicators. Accelerated urbanization in China not only creates economic opportunities, but also risk-management challenges for policy-makers to deal with major climate hazards. Urban systems need to become more resilient when dealing with the increasing meteorological/climate risks posed by future climate change. By taking into account the exposure and vulnerability of the existing infrastructures and inhabitants of the city environment as presented in this research, policy-makers will be able to develop better mitigation and adaptation decisions so as to effectively cope with the new challenges posed by future climate change. In other words, it is very important for both policy researchers and policy-makers to be forward thinking about land use, energy efficiency, population growth, and urban built environment in order to make cities flexible and resilience when facing climate change challenges.

We applied the above index-based climate risk assessment framework to five key infrastructure sectors in six representative cities in the Yangtze River Delta region. Our risk assessment is based on the diverse opinions of various infrastructure managers and other stakeholders, and our framework provides an effective way to consolidate these diverse opinions and aggregate them into intuitively comparable graphs. These graphs intuitively show that a high level of exposure is not automatically associated with a high level of vulnerability across our selected sample cities. The association of high exposure and low vulnerability, in Shanghai, Hangzhou, and Nanjing, is an indication of evolutionary adaptation of these three cities to the frequent climate hazards in the past. While Shanghai, Hangzhou, and Nanjing need to make further efforts to reduce their vulnerability towards future climate hazards, more urgent and much greater efforts are needed in those cities characterized by medium level of exposure but high level of vulnerability, such as Ningbo, Hefei, and Zhenjiang, to mitigate future climate risks and hazards.

These graphs, for the first time, provide first-hand insights into the aggregative understanding of various infrastructure managers and other stakeholders with regard to the current and future climate risk in their concerned areas. Nevertheless, the limited variation in the majority of cases is surprising. Many stakeholders may not yet have a solid understanding of risks posed by future climate change in their sector and region, and thus tending to take a conservative estimation. Contrasting opinions may cancel out in the aggregation process. To overcome the limitation caused by these two causes, future research should focus on the impact of key risks or risks associated with extreme climate events so that we are able to understand better to what extent these risks should be tackled and mitigated.

Supplementary Materials: The following are available online at http:/ /www.mdpi.com/2071-1050/11/7/2099/ s1.

Author Contributions: Conceptualization, H.Z. and L.S. (Laixiang Sun); Methodology, L.S. (Landong Sun), Z.T., H.Z., L.S. (Lanzhu Shao), L.F., and L.-F.J.; Software, G.D. and X.H.; Validation, L.S. (Lanzhu Shao); Formal Analysis, L.S. (Landong Sun), Z.T., G.D., and D.F.; Investigation, L.S. (Landong Sun), Z.T., H.Z., and X.H.; Resources, Z.T.; Writing-L.S. (Landong Sun), H.Z., L.S. (Laixiang Sun), and L.S. (Lanzhu Shao); Writing-Review and Editing, H.Z. and L.S. (Laixiang Sun); Visualization, L.S. (Landong Sun) and Z.T.

Funding: This work was funded by the National Natural Science Foundation of China (Grant Nos.51761135024, 41671113, and 41601049), the UK-China Research \& Innovation Partnership Fund through the Met Office Climate Science for Service Partnership (CSSP) China as part of the Newton Fund (Grant Nos. AJYG-643BJQ), The Engineering and Physical Sciences Research Council of UK (Grant Nos. R034214/1), The Netherlands Organisation for Scientific Research (NWO) (Grant Nos. ALWSD.2016.007), and the National Key Research and Development Program of China (Grant No. 2016YFC0502702).

Acknowledgments: We acknowledge valuable assistance from Zhuoran Liang at Hangzhou Met Office, Zhejiang Province, and Jie Yang at Jiangsu Climate Center during the fieldwork of this project. We thank Austin Sandler for his efforts in improving our exposition.

Conflicts of Interest: The authors declare no conflict of interest. 


\section{References}

1. Van de Sluijs, J.P. Uncertainty and dissent in climate risk assessment: A post-normal perspective. Nat. Cult. 2012, 7, 174-195. [CrossRef]

2. Howarth, C.; Morse-Jones, S.; Kythreotis, A.P.; Brooks, K. Co-producing UK climate change adapation policy: An analysis of the 2012 and 2017 UK Climate Change Risk Assessments. Enviorn. Sci. Policy 2018, 89, 412-420. [CrossRef]

3. Intergovernmental Panel on Climate Change. Managing the Risks of Extreme Events and Disasters to Advance Climate Change Adaptation; Intergovernmental Panel on Climate Change: Cambridge, UK, 2012.

4. Granberg, M.; Glover, B. Adaptation and Maladaptation in Australian national climate change policy. J. Environ. Plan. Policy Manag. 2014, 16, 147-159. [CrossRef]

5. Massey, E.; Huitema, D. The emergence of climate change adapation as a new field of public policy in Europe. Reg. Enviorn. Chang. 2016, 16, 553-564. [CrossRef]

6. Kaspersen, P.S.; Halsnaes, K. Integrated climate change risk management: A practical application for urban flooding during extreme precipitation. Clim. Serv. 2017, 6, 55-64. [CrossRef]

7. Wu, S.; Pan, T.; He, S. Climate change risk research: A case study on flood disaster risk in China. Adv. Clim. Chang. Res. 2012, 3, 92-98.

8. Millar, C.I.; Stephenson, N.L.; Stephens, S.L. Climate change and forests of the future: Managing in the face of uncertainty. Ecol. Appl. 2007, 17, 2145-2151. [CrossRef]

9. Nemet, G.F.; Holloway, T.; Meier, P. Implications of incorporating air-quality co-benefits into climate change policymaking. Environ. Res. Lett. 2010, 5, 014007. [CrossRef]

10. Li, Y.; Ye, W.; Wang, M.; Yan, X. Climate change and drought: A risk assessment of crop-yield impacts. Clim. Res. 2009, 39, 31-46. [CrossRef]

11. Nguyen, T.T.X.; Bonetti, J.; Rogers, K.; Woodroffe, C.D. Indicator-based assessment of climate-change impacts on coasts: A review of concepts, methodological approaches and vulnerability indices. Ocean Coast. Manag. 2016, 123, 18-43. [CrossRef]

12. Tapia, C.; Abajo, B.; Feliu, E.; Mendizabal, M.; Martinez, J.A.; Fernández, J.G.; Laburu, T.; Lejarazu, A. Profiling urban vulnerabilities to climate change: An indicator-based vulnerability assessment for European cities. Ecol. Indic. 2017, 78, 142-155. [CrossRef]

13. Tate, E. Uncertainty Analysis for a Social Vulnerability Index. Ann. Assoc. Am. Geogr. 2013, 103, 526-543. [CrossRef]

14. Harvey, A.; Hinkel, J.; Horrocks, L.; Klein, R.J.T.; Lasage, R.; Hodgson, N.; Sajwaj, T.; Benzie, M. Preliminary Assessment and Roadmap for the Elaboration of Climate Change Vulnerability Indications at Regional Level; AEA: London, UK, 2009.

15. Hinkel, J. Indicators of vulnerability and adaptive capacity: Towards a clarification of the science-policy interface. Glob. Environ. Chang. 2011, 21, 198-208. [CrossRef]

16. Schröter, D.; Cramer, W.; Leemans, R.; Prentice, I.C.; Araujo, M.B.; Arnell, N.W.; Bondeau, A.; Bugmann, H.; Carter, T.R.; Gracia, C.A.; et al. Ecosystem Service Supply and Vulnerability to Global Change in Europe. Science 2005, 310, 1333-1337.

17. Yohe, G.; Malone, E.L.; Brenkert, A.L.; Schlesigner, M.; Meij, H.; Lee, D. Geographic Distributions of Vulnerability to Climate Change. Integr. Assess. J. 2006, 6, 3.

18. Mahendra, R.S.; Mohanty, P.C.; Bisoyi, H.; Kumar, T.S.; Nayak, S. Assessment and management of coastal multi-hazard vulnerability along the Cuddaloree-Villupuram, east coast of India using geospatial techniques. Ocean Coast. Manag. 2011, 54, 302-311. [CrossRef]

19. Eriksen, S.H.; Kelly, P.M. Developing credible vulnerability indicators for climate adaptation policy assessment. Mitig. Adapt. Strateg. Glob. Chang. 2007, 12, 495-524. [CrossRef]

20. Tol, R.; Yohe, G. The weakest link hypothesis for adaptive capacity: An empirical test. Glob. Environ. Chang. 2007, 17, 218-227. [CrossRef]

21. Füssel, H. Review and quantitative analysis of indices of climate change exposure, adaptive capacity, sensitivity and impacts. In World Bank Development Report 2010: Development and Climate Change; World Bank: Potsdam, Germany, 2010. 
22. Van Velthuizen, V.; Huddelston, B.; Fischer, G.; Salvatore, M.; Ataman, E.; Nachtergaele, F.O.; Zanetti, M.; Bloise, M. Mapping Biophysical Factors That Influence Agricultural Production and Rural Vulnerability; FAO: Rome, Italy, 2007.

23. Moss, R.H.; Edmonds, J.A.; Hibbard, K.A.; Mannings, M.R.; Rose, S.K.; van Vuuren, D.P.; Carter, T.R. The next generation of scenarios for climate change research and assessment. Nature 2010, 463, 747-756. [CrossRef]

24. EB-CMDD. China Meteorological Disasters Dictionary (Zhejiang Vol.); China Meteorological Press: Beijing, China, 2006.

25. EB-CMDD. China Meteorological Disasters Dictionary (Shanghai Vol.); China Meteorological Press: Beijing, China, 2006.

26. EB-CMDD. China Meteorological Disasters Dictionary (Jiangsu Vol.); China Meteorological Press: Beijing, China, 2008.

27. Zhang, Y.; Fan, G.; He, Y.; Cao, L. Risk assessment of typhoon disaster for the Yangtze River Delta of China, Geomatics. Nat. Hazards Risk 2017, 8, 1580-1591. [CrossRef]

28. Wang, C.; Du, S.; Wen, J.; Zhang, M.; Gu, H.; Shi, Y.; Xu, H. Analyzing explanatory factors of urban pluvial floods in Shanghai using geographically weighted regression. Stoch. Environ. Res. Risk Assess. 2017, 31, 1777-1790. [CrossRef]

29. Chen, Q.; Ding, M.; Yang, X.; Hu, K.; Qi, J. Spatially explicit assessment of heat health risk by using multi-sensor remote sensing images and socioeconomic data in Yangtze River Delta, China. Int. J. Health Geogr. 2018, 17, 15. [CrossRef]

30. Xie, X.; Zheng, Y.; Pan, J. Urban Vulnerability and Adaptability to Climate Change: A Case Study of Cities in the Yangtze River Delta. Chin. J. Urban Environ. Stud. 2018, 6, 1850006. [CrossRef]

31. Du, H.; Wang, D.; Wang, Y. Influences of land cover types, meteorological conditions, anthropogenic heat and urban area on surface urban heat island in the Yangtze River Delta Urban Agglomeration. Sci. Total Environ. 2016, 571, 461-470. [CrossRef]

32. Huang, Q.; Lu, Y. The effect of urban heat island on climate warming in the Yangtze River Delta urban agglomeration in China. Int. J. Environ. Res. Public Health 2015, 12, 8773-8789. [CrossRef]

33. Nicholls, R.J. Adapation Options for Coastal Areas and Infrastrature: An Analysis for 2030; Report to the UNFCCC; UNFCCC: Bonn, Germany, 2007.

34. Rajbhandari, R.; Shrestha, A.B.; Kulkarni, A.; Patwardhan, S.K.; Bajracharya, S.R. Projected changes in climate over the Indus river basin using a high resolution regional climate model (PRECIS). Clim. Dyn. 2015, 44, 339-357. [CrossRef]

35. Rao, K.K.; Patwardhan, S.K.; Kulkarni, A.; Kamala, K.; Sabade, S.S.; Kumar, K.K. Projected changes in mean and extreme precipitation indices over India using PRECIS. Glob. Planet. Chang. 2014, 113, 77-90. [CrossRef]

36. Zhu, J.; Huang, G.; Wang, X.; Cheng, G.; Wu, Y. HIgh-resolution projections of mean and extreme precipitations over China through PRECIS under RCPs. Clim. Dyn. 2018, 50, 4037-4060. [CrossRef] 